\title{
The card of rehabilitative appraisal hospital worker in the PMIC
}

\author{
D De Buono \\ From de Senectute: Age and Health Forum \\ Catanzaro, Italy. 5-7 December 2009
}

The PMIC represents an important instrument for the arrangement and organization of the relative data of the patients hit from a cerebral ictus. In particular the appraisal card used during the rehabilitative phase concurs to consider numerous relative aspects to the patient with ictus, besides the identification of the given municipalities of pz (the sex, age, type of ictus, side hit, concomitant pathologies,) it uses the Motricity Index, the Canadian Scales, the anamnestico Rankin and puts effect into them, the Depression scales, the presence of alteration of the sensibility, the Scale of modified Barthel. The card is given at the income and to the resignations from the unit. It seems useful to add FIM to the appraisal card because the definition of the result works obtained them. The use of this Protocol of Minim of the Cerebral Ictus represents a moment of recording and arrangement of the several coming data from setting the rehabilitative ones and could be used in order to verify the real effectiveness of the rehabilitative treatment for the programme of the rehabilitative participation in the territorial phase and $\backslash$ or hospital worker.

Published: 19 May 2010

Submit your next manuscript to BioMed Central and take full advantage of:

- Convenient online submission

- Thorough peer review

- No space constraints or color figure charges

- Immediate publication on acceptance

- Inclusion in PubMed, CAS, Scopus and Google Scholar

- Research which is freely available for redistribution

Submit your manuscript at www.biomedcentral.com/submit
C Biomed Central 